\title{
Identification of SNP and SSR markers in eggplant using RAD tag sequencing
}

\author{
Lorenzo Barchi ${ }^{1,2}$, Sergio Lanteri ${ }^{1}$, Ezio Portis ${ }^{1 *}$, Alberto Acquadro ${ }^{1}$, Giampiero Valè ${ }^{3}$, Laura Toppino ${ }^{2}$ and \\ Giuseppe Leonardo Rotino ${ }^{2}$
}

\begin{abstract}
Background: The eggplant (Solanum melongena L.) genome is relatively unexplored, especially compared to those of the other major Solanaceae crops tomato and potato. In particular, no SNP markers are publicly available; on the other hand, over 1,000 SSR markers were developed and publicly available. We have combined the recently developed Restriction-site Associated DNA (RAD) approach with Illumina DNA sequencing for rapid and mass discovery of both SNP and SSR markers for eggplant.

Results: RAD tags were generated from the genomic DNA of a pair of eggplant mapping parents, and sequenced to produce $\sim 17.5 \mathrm{Mb}$ of sequences arrangeable into $\sim 78,000$ contigs. The resulting non-redundant genomic sequence dataset consisted of $\sim 45,000$ sequences, of which $\sim 29 \%$ were putative coding sequences and $\sim 70 \%$ were in common between the mapping parents. The shared sequences allowed the discovery of $\sim 10,000$ SNPs and nearly 1,000 indels, equivalent to a SNP frequency of 0.8 per $\mathrm{Kb}$ and an indel frequency of 0.07 per Kb. Over 2,000 of the SNPs are likely to be mappable via the Illumina GoldenGate assay. A subset of 384 SNPs was used to successfully fingerprint a panel of eggplant germplasm, producing a set of informative diversity data. The RAD sequences also included nearly 2,000 putative SSRs, and primer pairs were designed to amplify 1,155 loci.
\end{abstract}

Conclusion: The high throughput sequencing of the RAD tags allowed the discovery of a large number of DNA markers, which will prove useful for extending our current knowledge of the genome organization of eggplant, for assisting in marker-aided selection and for carrying out comparative genomic analyses within the Solanaceae family.

\section{Background}

Eggplant (Solanum melongena L., $2 \mathrm{n}=2 \mathrm{x}=24$ ) is a species belonging to the Solanaceae family. It is assumed to have been first domesticated in South and East Asia [1], and brought to Europe by Arab traders and immigrants around $600 \mathrm{CE}[2]$. In production terms, eggplant is the third most important Solanaceae crop species (after potato and tomato; http://faostat.fao. org), and is cultivated all over the world, but most intensively in China and India. About $2.4 \%$ of world production in 2009 is sited in Europe, with Italy being the single largest producer.

The estimated genome size of eggplant is $1.1 \mathrm{Gbp}$ [3]. Knowledge of its genome organization is rather limited

\footnotetext{
* Correspondence: ezio.portis@unito.it

'DIVAPRA Plant Genetics and Breeding, University of Torino, 10095

Grugliasco, Torino, Italy

Full list of author information is available at the end of the article
}

compared to that of either tomato or potato (http://solgenomics.net/, http://www.potatogenome.net). Genetic maps based on both inter-specific [4,5] and intra-specific [6-9] crosses have been developed. The most recent inter-specific map [5] is constituted of 347 COS and RFLP markers spanning $1,535 \mathrm{cM}$, while the most recent intra-specific maps were constructed by Barchi et al. [9] and Nunome et al. [8] and comprise 238 markers, spanning 718.7, and 236 markers, spanning $951.4 \mathrm{cM}$, respectively. Nevertheless the level of marker saturation is still low in the context of both fine mapping and genomic synteny. A small set of SSR markers was developed by Stagel et al. [10] from genic DNA sequence lodged in public access databases, while Nunome et al. [7] reported the identification of over 1,000 SSR markers from a screen of enriched gDNA and cDNA libraries. Many of these latter proved informative for intra-specific mapping and have been used to generate what is
Ciomed Central

() 2011 Barchi et al; licensee BioMed Central Ltd. This is an Open Access article distributed under the terms of the Creative Commons Attribution License (http://creativecommons.org/licenses/by/2.0), which permits unrestricted use, distribution, and reproduction in any medium, provided the original work is properly cited. 
currently the best available genetic linkage map. More recently, Fukuoka et al. [11] have published a dataset containing a large number $(\sim 16,000)$ of transcript sequences, but these have yet to be mined for either SSR or SNP markers.

The so-called "Restriction-site Associated DNA" (RAD) method was proposed by Miller et al. [12] as providing a reliable means for genome complexity reduction. The concept is based on acquiring the sequence adjacent to a set of particular restriction enzyme recognition sites. The application of high throughput sequencing technology has allowed significant progress in developing a RAD genotyping platform [13]; specifically, large volumes of polymorphism data can be now generated by applying massively parallel sequencing and multiplexing with RAD tag libraries.

In this report we describe the generation of genomic RAD tags from the two parents of an $F_{2}$ segregating population used to generate an intra-specific eggplant genetic map [9]; the RAD tags were sequenced using the Illumina platform and then annotated/categorized. These data allowed the discovery of a large number of SNP, indel and SSR markers, and some of the SNPs have been tested against a panel of eggplant accessions.

\section{Results and Discussion}

\section{Sequencing and contig assembly}

The sequencing procedure (Figure 1) generated 10.90 million reads for '305E40' and 12.12 million for '67/3', parents of an $\mathrm{F}_{2}$ intra-specific mapping population (see methods section), equivalent to $\sim 13.3 \mathrm{Mb}$ of sequence for '305E40' and 13.8 Mb for '67/3'. After editing/trimming, $\sim 17.5 \mathrm{Mb}$ high quality sequence was available. Raw data have been made available through the

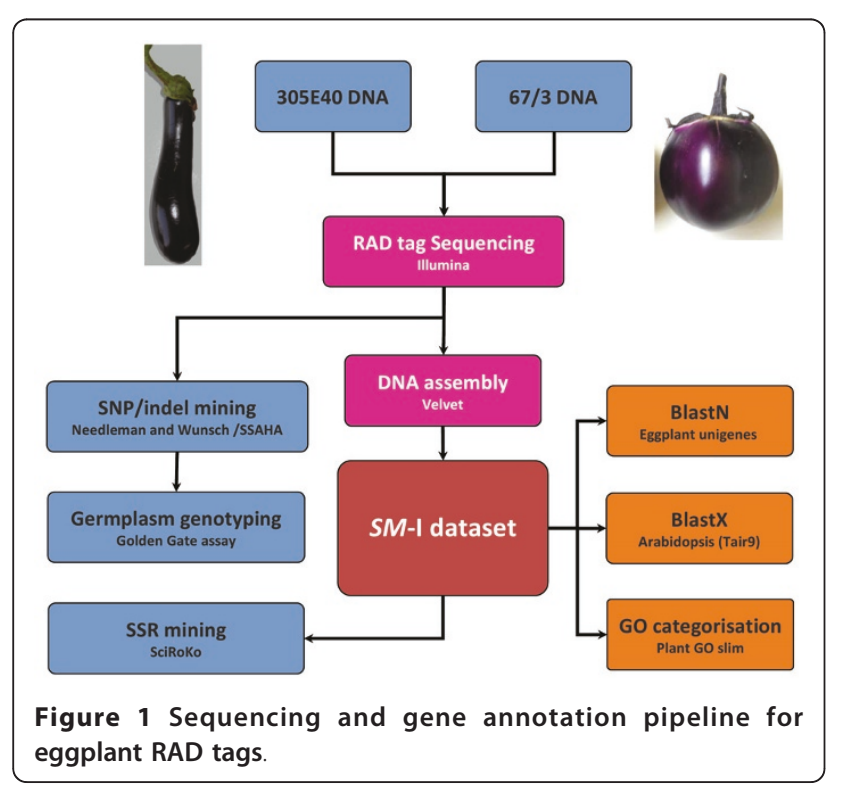

Sequence Read Archive (SRA) repository at NCBI (SRA035360.1). The reads were assembled into 77,876 contigs $(38,935$ from ' $305 E 40$ ', 38,941 from ' $67 / 3$ '); the '305E40' assemblies were of mean length 351 bp (range: 218-585 bp; N50: 362 bp), and those from '67/3' of mean length 368 bp (range: 218-579 bp; N50: 382 bp). The SM-I (Solanum melongena-Illumina) dataset finally comprised 45,390 sequences, including 31,635 sequences (12.5 Mbp) in common between the two mapping parents (Table 1), and formed the basis of the subsequent annotation and functional categorization (Additional file $1)$. The $S M-I$ dataset was also screened for the occurrence of repetitive elements. About 6.7\% (1.1 Mbp) of the sequence database showed some similarity with known plant mobile elements and was thus filtered out for SNP mining procedures.

\section{Sequence annotation}

In all, 6,411 sequences (14.1\%) of the $S M-I$ dataset matched 4,761 entries in the Fukuoka $16 \mathrm{~K}$ eggplant annotated unigene dataset (later referred as $16 \mathrm{~K}$ ) [11]. A BlastN search of the SGN Cornell unigene database (http://solgenomics.net/) produced significant hits from 9,476 (20.9\%) of the $S M-I$ sequences matching 8,244 SGN unigenes, of which $\sim 47 \%$ originated from tomato, $\sim 38 \%$ from potato, and $\sim 11 \%$ from tobacco. Combining the $16 \mathrm{~K}$ and $\mathrm{SGN}$ hits produced 12,315 unique sequences; a total of 9,976 sequences were properly annotated, of which 2,123 were annotated in both the SGN and $16 \mathrm{~K}$ databases, 6,440 only in SGN, and 1,413 only in $16 \mathrm{~K}$. Some 35,414 SM-I sequences were unrepresented in either of these two databases, and these were used as a batch BlastX query against the TAIR9 Arabidopsis thaliana protein database to allow a putative assignment of function. In all, 2,798 sequences (7.9\%) produced a hit with an $E$ value of $<\mathrm{e}^{-15}$,

Table 1 Summary statistics of the RAD tags sequencing via Illumina (San Diego, CA)

\begin{tabular}{lcc}
\hline Feature & 305E40 & $\mathbf{6 7 / 3}$ \\
\hline Illumina reads (million) & 10.90 & 12.12 \\
Mb of sequences & 13.30 & 13.82 \\
Total Mb after sequence editing & 17.50 \\
Contigs & 38,935 & 38,941 \\
Average contig length (bp) & 351 & 368 \\
N50' (bp) & 362 & 382 \\
Contig length range (bp, min-max) & $218-585$ & $218-579$ \\
Singlets & 6,912 & 6,843 \\
Common Contigs between parents & \multicolumn{3}{c}{31,635} \\
Number of sequences with SNPs & 5,174 & \\
Total SNPs (frequency) & $10,089(1 / 1,241$ bp) \\
Total InDels (frequency) & $874(1 / 14,325$ bp) \\
\hline
\end{tabular}

${ }^{1}$ N50: weighted median statistic such that $50 \%$ of the entire assembly is contained in the number of contigs equal to or greater than this value 
corresponding to $1,853 \mathrm{~A}$. thaliana genes. This rather small number of hits presumably reflects sequence divergence between eggplant and A. thaliana orthologs, although it has been recognized that the BLAST algorithm can be rather inefficient in identifying homologous sequences when short reads are involved [14]. Globally, therefore, the $S M-I$ dataset consists of some 12,774 annotated sequences which match 7,191 A. thaliana loci (Additional file 2).

\section{GO categorization}

The annotated SM-I sequences were functionally assigned using their $A$. thaliana orthologs as input (AGI codes) (Additional file 2), these functions were then arranged into GO slim categories (Figure 2) [15]. Since a given gene product can be associated with more than one GO term, the total number of GO terms exceeded that of the unigenes $[14,16]$. The eggplant $S M-I$ sequences resolved into 24,522 GO terms associated with "biological process", 15,137 with "cellular component" and 12,144 with "molecular function". The "response to biotic stimulus" category applied to 492 sequences (290 GO terms), among which the majority was related to the defense response against bacterial
(22.1\%), nematode (10.3\%) and fungal (9.3\%) infection. These sequences, especially the fungal response ones, are of particular interest, as '305E40' carries a major gene conferring resistance to Fusarium oxysporum f. sp. melongenae $[9,17]$. Among the "response to abiotic stimulus" sequences (937 sequences, 737 GO terms), $19.5 \%$ were associated with the response to salinity stress, $12.3 \%$ to low temperature and $7.7 \%$ to high temperature. Globally, the sequences were assigned to a wide range of gene ontology categories, indicating that a wide representation of transcripts was originally present in the RAD tags. Since about 12,000 SM-I eggplant sequences were annotated, it seems plausible to assume that we were able to capture a consistent fraction of the eggplant gene space.

\section{SNP identification}

Just over 10,000 SNPs were identified between the mapping parents, involving 5,179 of the 31,635 shared sequences (later referred as $10 \mathrm{~K}$, Additional file 3), as well as 874 indels (Table 1). To minimize false positives with respect to the SNPs, paired-end reads and SNP calling based on deep multiple alignment (minimum 6x coverage) were applied. The global inter-samples SNP

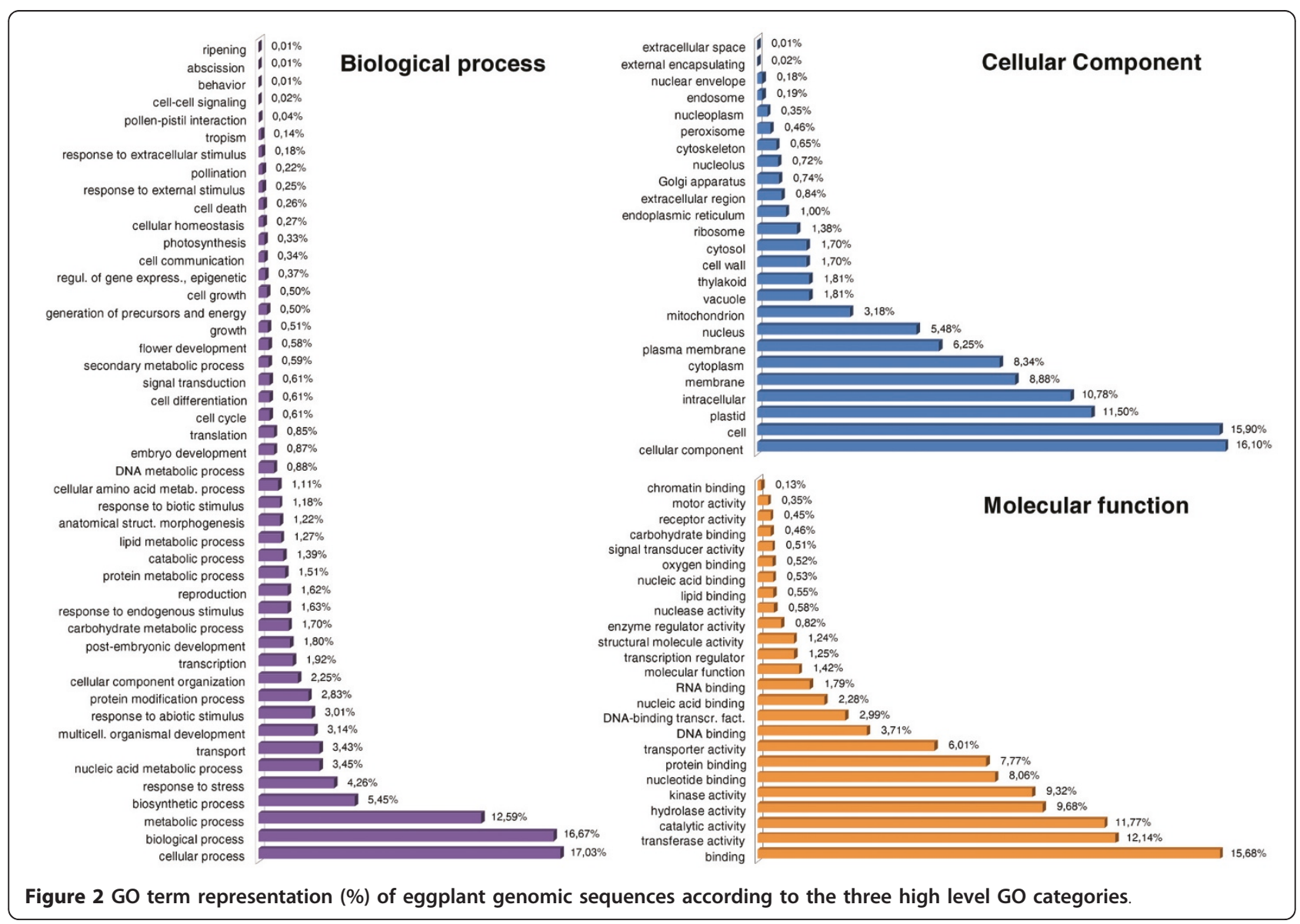


frequency was 0.8 per $\mathrm{Kb}$, and the indel frequency 0.07 per $\mathrm{Kb}$. We report the current SNP frequency as mostly belonging to the un-transcribed portion of the eggplant genome since we adopted two endonucleases recognizing GC-rich sites, being one methylation sensitive (SgrAI). This SNP frequency is lower than has been detected in potato (11.5 per $\mathrm{Kb}$; [18]), grapevine (2.5 per $\mathrm{Kb}$ in coding and 5.5 in non-coding sequence; [19]), barley (6.3 per $\mathrm{Kb}$ in coding sequence; [20]), maize (8.9 per $\mathrm{Kb}$ in coding sequence; [20]) and Citrus spp. (6.1 per $\mathrm{Kb}$; $[21])$, but is similar to that found in tomato $(0.6$ per $\mathrm{Kb}$; [22]), sweet pepper (1.0 per $\mathrm{Kb}$; [23]), rice (1.7 per $\mathrm{Kb}$; [24]) and confirmed the low level of intra-specific genetic polymorphism previously observed in eggplant [9]. As pointed out by Schneider et al. [25], however, inter-specific comparisons of SNP frequency are problematic, given that polymorphism is germplasm, genomic context- and mating system-dependent. About two thirds of the SNPs proved to be transitions (Figure 3), which have generally been found to be the predominant type [23,25-27]. The transition/transversion ratio has been suggested to be high in a situation where a low level of genetic divergence applies, decreasing as the genetic distance between the comparator genomes rises $[28,29]$. The relatively high ratio of 1.65 probably therefore reflects the overall low level of polymorphism between the two mapping parents, as is generally the case within the cultivated gene pool of eggplant [10]. A rather high frequency of $\mathrm{C} / \mathrm{T}$ alleles was observed, as also noted for bean [30], maize [27] and Citrus spp. [21,31]. In about 25\% of the SNP loci, there was no additional sequence variation in either the upstream or the downstream $60 \mathrm{bp}$ and almost all of them $(2,354$ out of 2,435$)$ were associated with a quality score $>0.4$ (the minimum threshold for the GoldenGate assay) and 2,201 produced a score of $>0.6$. The identification of > 10,000 potential SNPs is clearly a major advance for eggplant genotyping; incorporation of a sample of the 2,354 high quality SNPs into a GoldenGate assay would certainly saturate the '305E40' × '67/3'

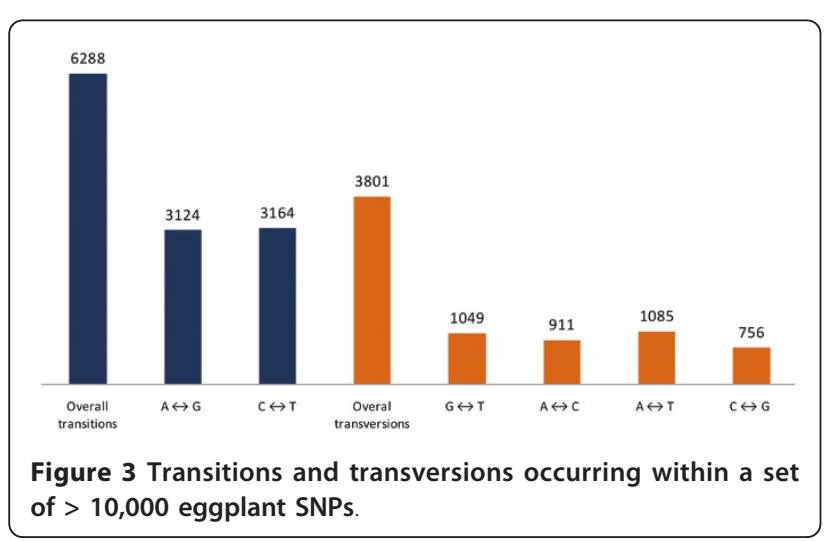

linkage map, while many of the remaining $~ 8,000$ SNPs could be assayed by other technologies, such as the Affymetrix SNP chip or the High Resolution Melting technique [32].

The successful identification of a large number of SNP (and indel and SSR) markers highlights the utility of the RAD approach for uncovering genome-wide polymorphisms, especially in materials with low polymorphism [33]. The versatility of the method lies in the ease with which different samples of the genome can be accessed merely by changing the identity of the restriction enzyme(s) used to cleave the genomic DNA; its particular advantage in the context of SNP discovery lies in the ease of aligning short DNA fragments between contrasting templates. Note also that the application of Illumina sequencing allowed for the identification of polymorphic sites outside of the restriction enzyme recognition site [13].

\section{Genetic diversity revealed by SNP markers}

A sample of 384 of the 2,201 highest quality SNPs (score > 0.6) was assembled into a GoldenGate assay, which was then applied to genotype $23 \mathrm{~S}$. melongena templates (Table 2), a representative panel of eggplant germplasm which captured a large part of variation with respect to fruit shape and colour (including '305E40'

Table 2 Solanum melongena lines genotyped with SNP markers (shape and skin colour are indicated)

\begin{tabular}{ll}
\hline Genotype & Fruit type \\
\hline 305 E40 & Long dark purple \\
DR2 & Long dark purple \\
TAL1/1 & Long dark purple \\
MSP 55-08 & Long dark purple \\
L422-08 & Long dark purple \\
L717-289 & Long dark purple \\
Dadali & Long light purple \\
Dourga & Long white \\
TB E80 & Oval dark purple \\
Fant E13 & Oval dark purple \\
Fant E27 & Oval dark purple \\
Fant E63 & Oval dark purple \\
Uga & Oval dark purple \\
Bin 6 & Oval green \\
S 600-1 & Oval purple \\
Floralba & Oval white \\
16-09 1 & Round dark purple \\
$67 / 3$ & Round violet \\
Qiyeqie & Round violet \\
Mel sais (violetta) & Round violet \\
Violetta di Siracusa & Round violet \\
Violetta di Toscana & Round violet \\
Bianca Sicilia & Round white \\
\hline &
\end{tabular}


and '67/3'), together with one accession of S. aethiopicum. Of these, 343 produced non- ambiguous data, a percentage in agreement with that previously reported in maize [34] and soybean [35]. The two duplicated genotypes included as internal controls gave consistent calls, indicating that the assay was highly robust. The frequency of missed calls was $\sim 0.6 \%$ among the eggplant templates, but was $16.0 \%$ for the S. aethiopicum template. PIC values ranged from 0.29 to 0.5 (mean 0.43 ), with 240 of the markers producing a PIC value > 0.4 , a level which is suitable for genetic diversity analyses. The phylogeny of the germplasm accessions based on these SNPs suggested the presence of two major clades (Figure 4); one included '305E40' together with its progenitors 'Dourga', 'Tal1/1', 'DR2' and S. aethiopicum, while the second included '67/3'. Within each of these major clades, a number of sub-clades correlated with fruit shape could be recognized. Thus, the phenotypic divergence between the pair of mapping parents appears to be representative of the genetic variation present within the cultivated gene pool.

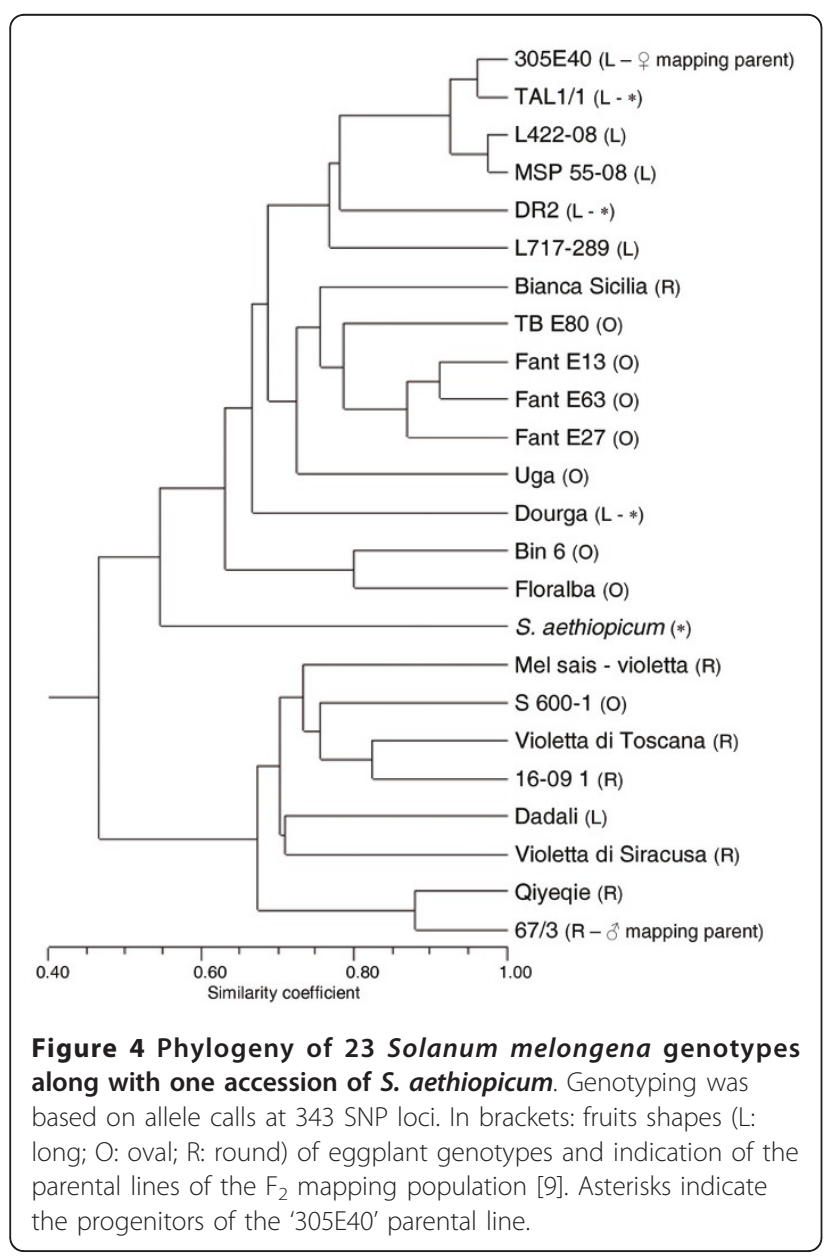

\section{Identification of SSRs}

A screen of the $S M-I$ dataset resulted in the identification of 1,797 sequences containing 1,877 putative SSRs. A small number of these SSRs (22) were discarded as they had already been previously identified $[7,10,11]$. The SSR was present in both mapping parents for 1,145 sequences, in '305E40' alone for 381 sequences, and in '67/3' alone for 329 sequences. At least 1,119 sequences permitted the design of PCR primers, leading to the generation of 1,155 putative markers (Additional file 4). About $4.1 \%$ of the $S M-I$ sequences contained an SSR (equivalent to a density of one SSR per $9.0 \mathrm{~Kb}$ ), which is comparable to the success rate recorded from ESTs of eggplant $[7,10]$ and tomato [36], somewhat higher than in potato [36] but lower than in either coffee [36] or sweet pepper [36,37]. Thus the RAD technique appears to offer an effective means of discovering SSRs, especially given the understanding that SSRs are more common in transcribed rather than in genomic sequences [38].

The most abundant repeat motif among the RAD SSRs were trinucleotides (34.6\%), followed by dinucleotides (18.6\%) and pentanucleotides (16.6\%) (Table 3), consistent with the observations of Stagel et al. [10]. The most common di- and tri-nucleotide motifs were AT (9.6\%) and AAC (19.0\%) (Table 4), in contrast to the observation in a previous study, where AG and AAG were the predominant motifs [10,14,36-39]. On the other hand Shirasawa et al. [40] showed that among tomato genomic SSRs, AAT is the most abundant trinucleotide and AT the most abundant dinucleotide motif, while in wheat, AAC is the predominant trinucleotide SSR motif [41]. SSRs composed of either AGG and CCG repeats were rather rare, as reported by Stagel et al. [10] in eggplant but also in other recent studies on Epimidium sagittatum [14] and Vigna radiata [42]. These particular motifs are relatively uncommon in dicotyledonous plant genomes [14,36], although they do feature in monocotyledonous ones [38,43]. Among the 160 mononucleotide SSRs detected, 151 were A/T; these loci have been suggested as providing a means of filling gaps in linkage maps constructed with higher order SSRs [36].

\section{Conclusions}

The RAD method was highly successful for the rapid and large-scale discovery of DNA markers, even in a species recognized to be low polymorphic. Applied to a pair of eggplant mapping parents, the approach was able to define over 10,000 SNPs, 1,600 indels and 1,800 putative SSRs. The current eggplant genetic maps are far from saturated, and as such have had little impact on breeding. The early maps were based on a wide cross, as this was considered necessary to achieve a sufficient level of polymorphism for the markers then available. 
Table 3 The 1,855 SSR motifs identified in 1,777 sequences

\begin{tabular}{|c|c|c|c|c|c|c|c|c|c|c|c|c|}
\hline \multirow[t]{2}{*}{ Motif } & \multirow[t]{2}{*}{ Counts } & \multirow[t]{2}{*}{$\%$} & \multirow[t]{2}{*}{ Average motif length } & \multicolumn{9}{|c|}{ Number of repeats } \\
\hline & & & & 3 & 4 & 5 & 6 & 7 & 8 & 9 & 10 & $>10$ \\
\hline Mononucleotide & 160 & 8.6 & 17.73 & - & - & - & - & - & - & - & - & 160 \\
\hline Dinucleotide & 345 & 18.6 & 19.46 & - & - & - & - & - & 107 & 67 & 47 & 124 \\
\hline Trinucleotide & 641 & 34.6 & 19.11 & - & - & 250 & 177 & 109 & 51 & 18 & 16 & 20 \\
\hline Tetranucleotide & 216 & 11.6 & 18.44 & - & 125 & 52 & 21 & 14 & 2 & 1 & - & 1 \\
\hline Pentanucleotide & 308 & 16.6 & 17.4 & 211 & 75 & 15 & 5 & 2 & - & - & - & - \\
\hline Hexanucleotide & 185 & 10.0 & 23.06 & 85 & 57 & 29 & 11 & 2 & 1 & - & - & - \\
\hline
\end{tabular}

With the rapid advances being made in sequencing technology, it is now possible to work with intra-specific crosses which are more relevant to the breeder. The present study has generated a large number of SNP, indel and SSR assays, which should permit the rapid saturation of the best available intra-specific genetic map [9].

Our primary goal was the identification of SNP markers, however data from RAD tags sequencing made it also possible the identification of SSR motifs and respective primers pairs for their amplification. The multi-allelic SSR markers are currently widely applied for both genetic mapping and diversity analyses, despite their cost for development and their limited throughput capabilities [44]. During the last few years the exploitation of publicly available EST sequences leaded to the identification of several thousands of new SSRs markers in a wide range of vegetables species like tomato, pepper, globe artichoke, Brassica, as well as eggplant $[10,36,37,39,44,45]$

Table 4 Frequencies and repeat numbers for the $\mathbf{2 0}$ most present SSR motifs

\begin{tabular}{lcccc}
\hline SSR motif & Counts & Average length & Counts/Mbp & \% of the Total \\
\hline AAC & 352 & 18.21 & 20.77 & 19.0 \\
AT & 179 & 19.09 & 10.53 & 9.6 \\
A & 151 & 17.66 & 8.88 & 8.1 \\
AG & 98 & 20.36 & 5.77 & 5.3 \\
AAG & 95 & 19.55 & 5.59 & 5.1 \\
AAAT & 90 & 18.53 & 5.29 & 4.8 \\
AAT & 87 & 21.78 & 5.12 & 4.7 \\
AAAAT & 77 & 17.83 & 4.53 & 4.1 \\
AC & 68 & 19.15 & 4.0 & 3.7 \\
AAAAG & 41 & 18.34 & 2.41 & 2.2 \\
ATC & 37 & 20.08 & 2.18 & 2.0 \\
AAAG & 36 & 18.56 & 2.12 & 1.9 \\
ACC & 26 & 18.85 & 1.53 & 1.4 \\
AAAAAT & 22 & 22.91 & 1.29 & 1.2 \\
AAATT & 21 & 17.62 & 1.24 & 1.1 \\
AATAT & 20 & 16.75 & 1.18 & 1.1 \\
AGG & 18 & 20.67 & 1.06 & 1.0 \\
AAAAC & 18 & 17.0 & 1.06 & 1.0 \\
ATAC & 17 & 20.71 & 1.0 & 0.9 \\
\hline & & & & \\
\hline
\end{tabular}

The GoldenGate SNP array was highly robust for $S$. melongena germplasm, but also has potential for a widecross population as $84 \%$ of the loci were scorable in a contrast between cultivated eggplant and its relative $S$. aethiopicum. Since these DNA markers define a specific position in the eggplant genome, they should be useful for merging the various genetic linkage maps currently available, some of which include loci related to important agronomic traits. Finally, the markers are very informative for the analysis of genetic diversity, as well as for comparative studies across species within the Solanaceae family.

\section{Methods}

\section{Plant materials and DNA isolation}

DNA was extracted from the two eggplant lines '305E40' and ' $67 / 3$ ', which are the parents of an $F_{2}$ intra-specific mapping population [9]. The female parent, double-haploid line '305E40', produces long, highly pigmented dark purple fruit. The parent '305E40' is an introgression line derived from the somatic hybrid $S$. melongena cv. 'Dourga'(+)S. aethiopicum [46] which was backcrossed with a tetraploid plant of the eggplant line 'DR2' and then subjected to anther culture; an anther-derived dihaploid plant was backcrossed 4 times with the line 'Tal1/1', then selfed two times and, finally, made completely homozygous through anther culture $[17,44]$. The male parent, line '67/3', was an $\mathrm{F}_{8}$ selection from the intra-specific cross cvs. 'Purpura' $\times$ 'CIN2'. Its fruit is round and violet coloured. The DNAs extracted from a set of 23 accessions (including the two mapping parents) representative of the $S$. melongena gene pool (Table 2), together with an accession of S. aethiopicum (a progenitor of '305E40') were tested with a subset of the newly developed SNP assays. All DNA samples were extracted from young leaves, using the GenElute ${ }^{\mathrm{TM}}$ Plant Genomic DNA Miniprep kit (Sigma, St. Louis, MO), following the manufacturer's protocol.

\section{RAD library preparation, sequencing, assembly}

The RAD library was constructed at Floragenex Inc. (USA), according to the protocol described by Baird et al. [13], as follows. Genomic DNA (300 ng) was 
digested for $60 \mathrm{~min}$ at $37^{\circ} \mathrm{C}$ in a $50 \mu \mathrm{L}$ reaction containing $20 \mathrm{U}$ each of SgrAI and PstI (New England Biolabs, Beverly MA, USA). The reactions were stopped by holding at $65^{\circ} \mathrm{C}$ for $20 \mathrm{~min}$. The P1 adapter (a modified Illumina adapter, see Baird et al. [13] was ligated to the products of the restriction reaction, and the "barcoding" of the various samples was achieved with a set of index nucleotides in the P1 adapter sequence. A $2.5 \mu \mathrm{L}$ aliquot of $100 \mathrm{nM}$ P1 adapter was added to each sample, along with $1 \mu \mathrm{L} 10 \mathrm{mM}$ ATP (Promega), $1 \mu \mathrm{L} 10 \times$ NEB Buffer4, $1 \mu \mathrm{L}$ (equivalent to 1,000 U) T4 DNA ligase (Enzymatics, Inc) and $5 \mu \mathrm{L}$ water, and the reaction was incubated at room temperature for $20 \mathrm{~min}$, and then heat-inactivated $\left(20 \mathrm{~min}\right.$ at $\left.65^{\circ} \mathrm{C}\right)$. The reactions were then pooled and the products randomly sheared to a mean size of 500 bp using a Bioruptor (Diagenode). The material was electrophoresed through a $1.5 \%$ agarose gel, and the DNA in the range 300-800 bp isolated using a MinElute Gel Extraction Kit (Qiagen). The dsDNA ends were treated with end blunting enzymes (Enzymatics, Inc) to remove overhangs, and the samples purified by passing through a MinElute column (Qiagen). 3'-adenine overhangs were then added by the addition of $15 \mathrm{U}$ Klenow exo- (Enzymatics), followed by an incubation at $37^{\circ} \mathrm{C}$ for $10 \mathrm{~min}$. Following re-purification, $1 \mu \mathrm{L} 10 \mu \mathrm{M}$ P2 adapter (a modified Illumina adapter, see Baird et al. [13]) was ligated, as described above for P1. The samples were then purified as above, and eluted in a volume of $50 \mu \mathrm{L}$. Following quantification (Qubit fluorimeter), $20 \mathrm{ng}$ were taken as the template for a $100 \mu \mathrm{L}$ PCR containing $20 \mu \mathrm{L}$ Phusion Master Mix (NEB), $5 \mu \mathrm{L} 10 \mu \mathrm{M}$ P1 adapter primer (Illumina), $5 \mu \mathrm{L}$ $10 \mu \mathrm{M}$ P2 adapter primer (Illumina) and water. The Phusion PCR settings followed product guidelines (NEB) over 18 cycles. The amplicons were gel purified, the size range 300-700 bp was excised from the gel, its DNA content adjusted to $3 \mathrm{ng} / \mu \mathrm{L}$. RADs from each parent were sequenced on a Genome Analyzer II (Illumina, San Diego, CA) using paired end 54 bp sequence reads. The paired end sequences from each parent were pooled and segregated by single read RAD sequences. Velvet [47] was used to assemble consensus LongRead contigs from the paired end data. Repetitive element occurrence was searched via CENSOR, a software tool which screens query sequences against a reference collection of repeats (http://www.girinst.org/censor; [48]), adopting default parameters and considering Viridiplantae as target database.

\section{Sequence annotation}

CAP3 [49] algorithm was used to identify sequences in common between the mapping parents using default parameters with some modifications (overlap length cutoff $=80$ and overlap percent identity cut-off $=95$ ). The resulting dataset (SM-I; Solanum melongena-Illumina) included singlets from '67/3' and '305E40' as well as contigs deriving from both RAD rounds. A stand-alone BLAST tool was used to provide the optimal annotation for each dataset.

A BlastN search was performed against the SGN Cornell unigene database (http://solgenomics.net/), using as cut-off parameters $90 \%$ identity and a minimum alignment of $100 \mathrm{bp}$. A second BlastN search was made against the $16 \mathrm{~K}$ Fukuoka eggplant unigene dataset (in the article referred as $16 \mathrm{~K}$, http://vegmarks.nivot.affrc. go.jp[11]), using as cut-off parameters $95 \%$ identity and a minimum alignment of $100 \mathrm{bp}$. A BlastX search was carried out against the TAIR9 dataset (http://www.arabidopsis.org), adopting a threshold E-value of $\mathrm{e}^{-15}$. The annotated sequences were assigned a function based on the Gene Ontology tool available at TAIR (http://www. arabidopsis.org/tools/bulk/go/), using A. thaliana orthologs as input (AGI codes), and mapped to higher level categories (plant GO Slim) using GOSlimViewer [50] according to the three principal GO categories "molecular function", "biological process" and "cellular localization" [15].

\section{SNP discovery}

SNPs were called using a short read alignment algorithm [51] which aligned non-assembled 50 bp Illumina reads from ' $67 / 3$ ' against the ' $305 E 40$ ' assembly, by analogy with the MAQ style sequence pileup [52] at a minimum coverage of $6 x$; to call indels, an SSAHA-based alignment strategy [53] was applied. Both SNPs and indels were regarded as true polymorphisms, when each allele was observed at least three times.

Each SNP was assigned a designability score via a dedicated "assay design tool" (http://www.illumina.com), which identified SNP loci free of other polymorphisms $60 \mathrm{bp}$ either upstream or downstream. A quality score, based on the probability of good performance using the Illumina Golden Gate assay, was assigned to each SNP, where a score $>0.6$ indicated a high probability of success.

\section{Genetic diversity assessment based on the GoldenGate assay}

The GoldenGate assay (Illumina, San Diego, CA) was used for SNP genotyping at the UC Davis Genome Center. Automatic allele calling for each locus was obtained by GenCall software (Illumina). As an internal control, two duplicate templates were included in each run. An estimate of PIC (Polymorphism Information Content) was made following the suggestion of Anderson et al. [54]. Each SNP locus was scored in binary fashion. A co-phenetic distance matrix based on co-dominant markers was generated, as described by Smouse et al. [55] 
and used to construct a UPGMA-based dendrogram as implemented within NTSYS software package v2.10 [56].

\section{SSR identification}

SSR motifs were identified by SciRoKo software [57]. Both perfect and imperfect mono, di-, tri-, tetra-, pentaand hexanucleotide motifs were targeted. Primer pairs were designed from the flanking sequences using PRIMER3 software [58] in batch mode, as implemented in the SciRoKo package. The target amplicon size range was set as $125-250 \mathrm{bp}$, the optimal annealing temperature $60^{\circ} \mathrm{C}$, and the optimal primer length $20 \mathrm{bp}$.

\section{Additional material}

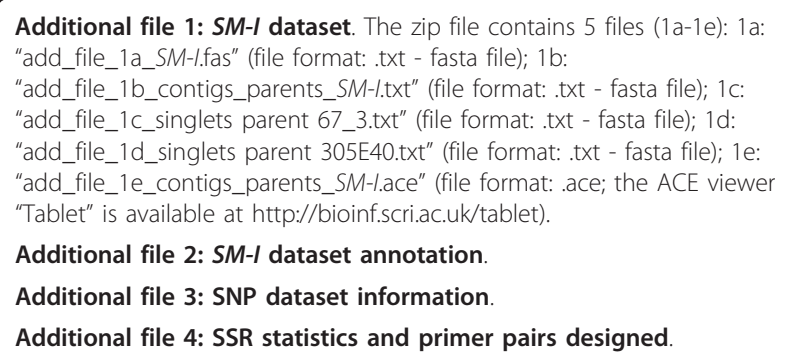

\section{Acknowledgements}

This research was partially supported by the Italian Ministry of Agricultural Alimentary and Forest Politics in the framework of "PROM", "ESPLORA" and "AGRONANOTECH" projects

\section{Author details}

'DIVAPRA Plant Genetics and Breeding, University of Torino, 10095 Grugliasco, Torino, Italy. ${ }^{2}$ CRA-ORL Research Unit for Vegetable Crops, 26836 Montanaso Lombardo, Lodi, Italy. ${ }^{3}$ CRA-GPG Genomic Research Centre, 29017 Fiorenzuola d'Arda, Piacenza, Italy.

\section{Authors' contributions}

SL and GLR planned and supervised the work. LB carried out BLAST analyses, SSR primer design and sequence annotation; EP carried out the diversity analysis, AA supervised the BLAST analyses, LT and GLR provided plant materials; GV contributed to SNP identification. All the authors read and approved the final version of the manuscript.

Received: 7 March 2011 Accepted: 10 June 2011

Published: 10 June 2011

\section{References}

1. Polignano G, Uggenti P, Bisignano V, Gatta Della C: Genetic divergence analysis in eggplant (Solanum melongena L.) and allied species. Genetic Resources and Crop Evolution 2010, 57(2):171-181.

2. Daunay M, Lester R, Ano G: Eggplant. In Tropical plant breeding. Edited by: Charrier, A, Jacquot, M, Hamon, S \& Nicolas, D. CIRAD, Paris, France; 199-222.

3. Arumuganathan K, Earle E: Nuclear DNA content of some important plant species. Plant Molecular Biology Reporter 1991, 9(3):208-218.

4. Doganlar S, Frary A, Daunay M, Lester R, Tanksley S: A comparative genetic linkage map of eggplant (Solanum melongena) and its implications for genome evolution in the Solanaceae. Genetics 2002, 161(4):1697-1711.

5. Wu F, Eannetta N, Xu Y, Tanksley S: A detailed synteny map of the eggplant genome based on conserved ortholog set II (COSII) markers. Theoretical and Applied Genetics 2009, 118(5):927-935
6. Nunome T, Ishiguro K, Yoshida T, Hirai M: Mapping of fruit shape and color development traits in eggplant (Solanum melongena L.) based on RAPD and AFLP markers. Breeding science 2001, 51(1):19-26.

7. Nunome T, Negoro S, Kono I, Kanamori H, Miyatake K, Yamaguchi H, Ohyama A, Fukuoka H: Development of SSR markers derived from SSRenriched genomic library of eggplant (Solanum melongena L.). Theoretical and Applied Genetics 2009, 119(6):1143-1153.

8. Nunome T, Suwabe K, Iketani H, Hirai M: Identification and characterization of microsatellites in eggplant. Plant Breeding 2003, 122(3):256-262.

9. Barchi L, Lanteri S, Portis E, Stagel A, Vale G, Toppino L, Rotino GL: Segregation distortion and linkage analysis in eggplant (Solanum melongena L.). Genome 2010, 53(10):805-815.

10. Stàgel A, Portis E, Toppino L, Rotino GL, Lanteri S: Gene-based microsatellite development for mapping and phylogeny studies in eggplant. BMC Genomics 2008, 9:357.

11. Fukuoka H, Yamaguchi H, Nunome T, Negoro S, Miyatake K, Ohyama A: Accumulation, functional annotation, and comparative analysis of expressed sequence tags in eggplant (Solanum melongena L.), the third pole of the genus Solanum species after tomato and potato. Gene 2010, 450(1-2):76-84

12. Miller MR, Dunham JP, Amores A, Cresko WA, Johnson EA: Rapid and costeffective polymorphism identification and genotyping using restriction site associated DNA (RAD) markers. Genome Research 2007, 17(2):240-248.

13. Baird NA, Etter PD, Atwood TS, Currey MC, Shiver AL, Lewis ZA, Selker EU, Cresko WA, Johnson EA: Rapid SNP Discovery and Genetic Mapping Using Sequenced RAD Markers. PLOS ONE 2008, 3(10):e3376.

14. Zeng S, Xiao G, Guo J, Fei Z, Xu Y, Roe B, Wang Y: Development of a EST dataset and characterization of EST-SSRs in a traditional Chinese medicinal plant, Epimedium sagittatum (Sieb. Et Zucc.) Maxim. BMC Genomics 2010, 11(1):94.

15. Harris M, Clark J, Ireland A, Lomax J, Ashburner M, Foulger R, Eilbeck K, Lewis S, Marshall B, Mungall C, Richter J, Rubin GM, Blake JA, Bult C, Dolan M, Drabkin H, Eppig JT, Hill DP, Ni L, Ringwald M, Balakrishnan R, Cherry JM, Christie KR, Costanzo MC, Dwight SS, Engel S, Fisk DG, Hirschman JE, Hong EL, Nash RS, et al: The Gene Ontology (GO) database and informatics resource. Nucleic Acids Research 2004, 32(Database):D258-261.

16. Varshney R, Hiremath $P$, Lekha P, Kashiwagi J, Balaji J, Deokar A, Vadez V Xiao Y, Srinivasan R, Gaur P, Siddique KHM, Town CD, Hoisington DA: A comprehensive resource of drought- and salinity-responsive ESTs for gene discovery and marker development in chickpea (Cicer arietinum L.). BMC Genomics 2009, 10:523.

17. Toppino L, Vale G, Rotino GL: Inheritance of Fusarium wilt resistance introgressed from Solanum aethiopicum Gilo and Aculeatum groups into cultivated eggplant (S.melongena) and development of associated PCRbased markers. Molecular Breeding 2008, 22(2):237-250.

18. Simko I, Haynes KG, Jones RW: Assessment of Linkage Disequilibrium in Potato Genome With Single Nucleotide Polymorphism Markers. Genetics 2006, 173(4):2237-2245

19. Velasco R, Zharkikh A, Troggio M, Cartwright DA, Cestaro A, Pruss D, Pindo M, Fitzgerald LM, Vezzulli S, Reid J, Malacarne G, lliev D, Coppola G, Wardell B, Micheletti D, Macalma T, Facci M, Mitchell JT, Perazzolli M, Eldredge G, Gatto P, Oyzerski R, Moretto M, Gutin N, Stefanini M, Chen Y, Segala C, Davenport C, Dematté L, Mraz A, et al: A High Quality Draft Consensus Sequence of the Genome of a Heterozygous Grapevine Variety. PLOS ONE 2007, 2(12):e1326.

20. Barker G, Edwards K: A genome-wide analysis of single nucleotide polymorphism diversity in the world's major cereal crops. Plant Biotechnology Journal 2009, 7(4):318-325.

21. Jiang D, Ye QL, Wang FS, Cao L: The Mining of Citrus EST-SNP and Its Application in Cultivar Discrimination. Agricultural Sciences in China 2010, 9(2):179-190.

22. Van Deynze A, Stoffel K, Buell CR, Kozik A, Liu J, van der Knaap E, Francis D: Diversity in conserved genes in tomato. BMC Genomics 2007, 8:9.

23. Jung J, Park S, Liu W, Kang B: Discovery of single nucleotide polymorphism in Capsicum and SNP markers for cultivar identification. Euphytica 2010, 175(1):91-107.

24. Feltus FA, Wan J, Schulze SR, Estill JC, Jiang N, Paterson AH: An SNP Resource for Rice Genetics and Breeding Based on Subspecies Indica and Japonica Genome Alignments. Genome Research 2004, 14(9):1812-1819. 
25. Schneider K, Kulosa D, Soerensen T, Mohring S, Heine M, Durstewitz G, Polley A, Weber E, Jamsari , Lein J, Hohmann U, Tahiro E, Weisshaar B, Schulz B, Koch G, Jung C, Ganal M: Analysis of DNA polymorphisms in sugar beet (Beta vulgaris L.) and development of an SNP-based map of expressed genes. Theoretical and Applied Genetics 2007, 115(5):601-615.

26. Riju A, Arunachalam V: Interspecific differences in single nucleotide polymorphisms (SNPs) and indels in expressed sequence tag libraries of oil palm Elaeis guineensis and E. oleifera. Available from Nature Preceding 2009 [http://precedings.nature.com/documents/3593/version/2].

27. Batley J, Barker G, O'Sullivan H, Edwards K, Edwards D: Mining for single nucleotide polymorphisms and insertions/deletions in maize expressed sequence tag data. Plant Physiology 2003, 132(1):84-91.

28. Holmquist R: Transitions and transversions in evolutionary descent: An approach to understanding. Journal of Molecular Evolution 1983, 19(2):134-144.

29. Yang Z, Yoder AD: Estimation of the Transition/Transversion Rate Bias and Species Sampling. Journal of Molecular Evolution 1999, 48(3):274-283.

30. Ramirez M, Graham M, Blanco-Lopez L, Silvente S, Medrano-Soto A, Blair M, Hernandez G, Vance C, Lara M: Sequencing and Analysis of Common Bean ESTs. Building a Foundation for Functional Genomics. Plant Physiology 2005, 137:1211-1227.

31. Terol J, Naranjo M, Ollitrault P, Talon M: Development of genomic resources for Citrus clementina: characterization of three deep-coverage BAC libraries and analysis of 46,000 BAC end sequences. BMC Genomics 2008, 9:423.

32. Wittwer CT, Reed GH, Gundry CN, Vandersteen JG, Pryor RJ: HighResolution Genotyping by Amplicon Melting Analysis Using LCGreen. Clinical Chemistry 2003, 49(6):853-860.

33. Wu $X$, Ren $C$, Joshi $T$, Vuong $T, X u$ D, Nguyen $H$ : SNP discovery by highthroughput sequencing in soybean. BMC Genomics 2010, 11(1):469.

34. Yan J, Yang X, Shah T, Sánchez-Villeda H, Li J, Warburton M, Zhou Y, Crouch J, Xu Y: High-throughput SNP genotyping with the GoldenGate assay in maize. Molecular Breeding 2010, 25(3):441-451.

35. Hyten D, Song Q, Choi I, Yoon M, Specht J, Matukumalli L, Nelson R, Shoemaker R, Young N, Cregan P: High-throughput genotyping with the GoldenGate assay in the complex genome of soybean. Theoretical and Applied Genetics 2008, 116(7):945-952.

36. Kumpatla S, Mukhopadhyay S: Mining and survey of simple sequence repeats in expressed sequence tags of dicotyledonous species. Genome 2005, 48:985-998.

37. Portis E, Nagy I, Sasvari Z, Stagel A, Barchi L, Lanteri S: The design of Capsicum spp. SSR assays via analysis of in silico DNA sequence, and their potential utility for genetic mapping. Plant Science 2007, 172:640-648.

38. Morgante $M$, Hanafey $M$, Powell W: Microsatellites are preferentially associated with nonrepetitive DNA in plant genomes. Nature Genetetics 2002, 30:194-200.

39. Nagy I, Stagel A, Sasvari Z, Roder M, Ganal M: Development, characterization, and transferability to other Solanaceae of microsatellite markers in pepper (Capsicum annuum L.). Genome 2007, 50:668-688.

40. Shirasawa K, Asamizu E, Fukuoka H, Ohyama A, Sato S, Nakamura Y, Tabata S, Sasamoto S, Wada T, Kishida Y, Tsuruoka H, Fujishiro T, Yamada M, Isobe S: An interspecific linkage map of SSR and intronic polymorphism markers in tomato. Theoretical and Applied Genetics 2010, 121(4):731-739.

41. Kantety R, La Rota M, Matthews D, Sorrells M: Data mining for simple sequence repeats in expressed sequence tags from barley, maize, rice, sorghum and wheat. Plant Molecular Biology 2002, 48:501-510.

42. Tangphatsornruang S, Sangsrakru D, Chanprasert J, Uthaipaisanwong P, Yoocha T, Jomchai N, Tragoonrung S: The Chloroplast Genome Sequence of Mungbean (Vigna radiata) Determined by High-throughput Pyrosequencing: Structural Organization and Phylogenetic Relationships. DNA Research 2010, 17(1):11-22.

43. La Rota M, Kantety R, Yu J, Sorrells M: Nonrandom distribution and frequencies of genomic and EST-derived microsatellite markers in rice, wheat, and barley. BMC Genomics 2005, 6:23.

44. Tang J, Baldwin S, Jacobs J, Van der Linden CG, Voorrips RE, Leunissen JAM, Van Eck HJ, Vosman B: Large-scale identification of polymorphic microsatellites using an in silico approach. BMC Bioinformatics 2008, 9:374.

45. Scaglione D, Acquadro A, Portis E, Taylor C, Lanteri S, Knapp S: Ontology and diversity of transcript-associated microsatellites mined from a globe artichoke EST database. BMC Genomics 2009, 10:454.
46. Rizza F, Mennella G, Collonnier C, Shiachakr D, Kashyap V, Rajam M, Prestera M, Rotino GL: Androgenic dihaploids from somatic hybrids between Solanum melongena and S. aethiopicum group gilo as a source of resistance to Fusarium oxysporum f. sp melongenae. Plant Cell Reports 2002, 20(11):1022-1032.

47. Zerbino DR, Birney E: Velvet: Algorithms for de novo short read assembly using de Bruijn graphs. Genome Research 2008, 18(5):821-829.

48. Kohany O, Gentles AJ, Hankus L, Jurka J: Annotation, submission and screening of repetitive elements in Repbase: RepbaseSubmitter and Censor. BMC Bioinformatics 2006, 7:474.

49. Huang X, Madan A: CAP3: A DNA Sequence Assembly Program. Genome Research 1999, 9(9):868-877.

50. McCarthy F, Wang N, Magee GB, Nanduri B, Lawrence M, Camon E, Barrell D, Hill D, Dolan M, Williams WP, Luthe DS, Bridges SM, Burgess SC: AgBase: a functional genomics resource for agriculture. BMC Genomics 2006, 7(1):229.

51. Needleman SB, Wunsch CD: A general method applicable to the search for similarities in the amino acid sequence of two proteins. Journal of Molecular Biology 1970, 48(3):443-453.

52. Li H, Ruan J, Durbin R: Mapping short DNA sequencing reads and calling variants using mapping quality scores. Genome Research 2008, 18(11):1851-1858.

53. Ning Z, Cox A, Mullikin J: SSAHA: A fast search method for large DNA databases. Genome Research 2001, 1725-1729.

54. Anderson J, Churcill G, Autrique J, Tanksley S, Sorrels M: Optimizing parental selection for genetic linkage maps. Genome 1992, 36:181-186.

55. Smouse PE, Peakall R: Spatial autocorrelation analysis of individual multiallele and multilocus genetic structure. Heredity 1999, 82(5):561-573.

56. Rohlf F: NTSYS-pc Numerical Taxonomy and Multivariate Analysis System version 2.02 User Guide. 1998.

57. Kofler R, Schlotterer C, Lelley T: SciRoKo: a new tool for whole genome microsatellite search and investigation. Bioinformatics 2007, 23(13):1683-1685.

58. Rozen S, Skaletsky H: Primer3 on the www for general users and for biologist programmers. Methods Molecular Biology 2000, 132:365-386.

doi:10.1186/1471-2164-12-304

Cite this article as: Barchi et al:: Identification of SNP and SSR markers in eggplant using RAD tag sequencing. BMC Genomics 2011 12:304.

\section{Submit your next manuscript to BioMed Central and take full advantage of:}

- Convenient online submission

- Thorough peer review

- No space constraints or color figure charges

- Immediate publication on acceptance

- Inclusion in PubMed, CAS, Scopus and Google Scholar

- Research which is freely available for redistribution

Submit your manuscript at www.biomedcentral.com/submit
C) Biomed Central 